Research Article

\title{
Social movements in a time of pandemic: The case of Tech4Covid19 in Portugal
}

\author{
Movimientos sociales en tiempos de pandemia: El caso de \\ Tech4Covid19 en Portugal
}

\author{
Fernando Almeida \\ University of Porto, ISPGAYA \& INESC TEC, Portugal. \\ Correspondence: almd@fe.up.pt
}

\begin{abstract}
The COVID-19 pandemic had a strong impact on Portuguese society and raised the need for new technological projects to help frontline professionals in the fight against coronavirus and its effects on the local population and economic agents. It is in this context that the Tech4Covid19 movement was founded by Portuguese technological startups. This initiative brings together more than 5000 volunteers and offers technological solutions in the areas of health, education, and local economy. This study aims to understand and explore the organizational model and dynamics of Tech4Covid19 through the adoption of qualitative methods based on primary and secondary sources that have allowed the movement to be explored from multiple perspectives. The findings reveal that Tech4Covid internally promotes the development of its own projects, but also accepts projects proposed by external entities that are aligned with the principles and values of the movement. The organization of the movement is supported by autonomous self-managed teams regarding each project, and there is a coordination group responsible for the aggregate management of the various initiatives and for establishing communication with partners, the media, and social networks.
\end{abstract}

Keywords: COVID-19; innovation; startups; technology; volunteering; crowdfunding.

Resumen: La pandemia de COVID-19 tuvo un fuerte impacto en la sociedad portuguesa y planteó la necesidad de nuevos proyectos tecnológicos para ayudar a los profesionales de primera línea en la lucha contra el coronavirus y sus efectos en la población local y los agentes económicos. En este contexto, se fundó el movimiento Tech4Covid19 por parte de startups tecnológicas portuguesas. Esta iniciativa reúne a más de 5.000 voluntarios y ofrece soluciones tecnológicas en las áreas de salud, educación y economía local. Este artículo pretende comprender y explorar el modelo organizativo y la dinámica de Tech4Covid19 mediante la adopción de métodos cualitativos basados en fuentes primarias y secundarias que han permitido explorar el movimiento desde múltiples perspectivas. Los resultados revelan que Tech4Covid promueve internamente el desarrollo de sus propios proyectos, pero también acepta proyectos propuestos por entidades externas que estén alineados con los principios y valores del movimiento. La organización del movimiento se apoya en equipos autónomos auto gestionados con respecto a cada proyecto, y existe un grupo de coordinación responsable de la gestión agregada de las distintas iniciativas y de establecer la comunicación con los medios de comunicación y las redes sociales.

Palabras clave: COVID-19; innovación; startups; tecnología; voluntariado; crowdfunding. 


\section{Introduction}

The crisis provoked by COVID-19 has completely different characteristics from the previous sovereign debt crisis in the EU countries of 2008. Some unique characteristics of this crisis should be remarkable. This crisis was motivated by a global and abrupt shock in which demand and supply were simultaneously destroyed. This situation occurs when the world is much more integrated, as demonstrated by the speed with which the COVID-19 spread throughout the world (Hennig, 2020). This crisis also comes at a time when governments are more in debt and therefore have less capacity to absorb shocks. Moreover, the economic impact of this crisis is asymmetric. For example, some industries like tourism are more affected than others. This means that the sectoral composition of countries will influence the impact of the crisis.

In an open economy like the Portuguese one, the negative effects of the COVID-19 pandemic were significantly felt. Firstly, COVID-19 forced the confinement of the population at home and the closure of non-essential economic activity. In this way, the effects of the crisis were felt in the main sectors of the economy and in the life of Portuguese companies and their employees. In a country where the business sector is mainly made up of small and medium-sized enterprises (SMEs), and where export activity represents $44 \%$ of the national GDP, the opening up of foreign markets to Portuguese goods and services will be a key factor in the recovery of economic activity. However, the business structure in Portugal is fundamentally aged and dominated by micro family companies (Marques \& Couto, 2017). Hence, startups with strong support in technology are more agile business structures with better conditions to adapt to sudden changes in the market, despite strong cash flow constraints.

As Seijts and Milani (2020) state, it is in the context of critical, volatile, and highly uncertain situations that the leaders of organizations assume a decisive role in society. Giones et al. (2020) refer that the startups due to the uncertainties of the management of their activities and difficulties in predicting the success of their commercial projects have the challenge in the short term to continue with their projects or adapt their activities to respond to the challenges posed by COVID-19. The Portuguese startups quickly sought to respond to the challenge of COVID-19 and converted their production activity to the manufacture of personal protective equipment that is in short supply in Portugal and the world. At the same time, apps were also developed with the fundamental objective of mitigating the economic and social effects of this crisis on the population and companies. On March 16, 2020, the Tech4Covid19 movement was created by the founders of Portuguese technological startups. This movement emerged from an informal conversation in which the founders of these companies wondered how they could organize themselves to respond to this crisis by developing technological solutions to combat the effects of the virus. There was a consensus that none of these companies alone would be able to respond to a challenge of this magnitude, but that together they could make a difference in the lives of many people and companies. In just six days the movement managed to gather 120 startups and more than 2500 people, who were working on about 20 autonomous projects to combat the new coronavirus. The Tech4Covid19 movement aims to bring together talent, resources, and technology to fight the spread of COVID-19 and the social, economic, and environmental problems that have arisen due to the pandemic. Furthermore, Tech4Covid19 strongly contributed to Portugal being considered by the Organization for Economic Co-operation and Development (OECD) as the country with the largest number of innovative projects in the fight against COVID19. It is currently the world's leading country in this area according to the OECD data (Simões, 2020).

This manuscript aims to explore the Tech4Covid19 organizational model and dynamics. The purpose of this work is to explore how a movement of this large dimension can be organized and coordinated, in which several projects coexist in parallel, and several companies from very different areas can come together and work towards a common goal. To achieve the proposed objective, qualitative methodologies were used through the analysis of primary information 
sources (i.e., interviews with the founders of the initiative) and secondary information sources (i.e., social networks, streaming video channels, press releases).

This paper is organized as follows: Initially, a theoretical contextualization on the role of digital technologies and the emergence of social movements is performed and the Tech4Covid19 initiative is presented. Next, the various phases of the study methodology are described. After that, the results are presented and discussed according to their relevance to understanding the organizational structure and dynamics of the movement. Finally, the conclusions are outlined, and the practical impact of this study is presented. In this section, the limitations of this study are also discussed, and some indications of future work are provided.

\section{Background}

\subsection{The Role of Digital Technologies}

The technological revolution has given rise to a desire and a need for companies to innovate and use technologies as a primary resource. The use of the Internet is now indispensable both for companies and enterprises. Through the use of information and communication technologies (ICT), it is possible to access a very diverse range of information in real-time, as well as to exchange data. In fact, the services have been simplified and facilitated by the adoption of ICT. A good example of this impact is teleworking, which was a measure widely adopted by companies to continue their activity in times of pandemic (Belzunegui-Eraso \& Erro-Garcés, 2020). However, technology has also been seen by some as an element that can pose new challenges in the society like the reduction of the human labor force (Dahlin, 2019; Gentili et al., 2020). However, this situation has fostered the emergence of specialized occupations in the ICT field, such as software engineers, digital marketing professionals, bloggers, or youtubers.

Various sectors of society are adopting technologies to combat the COVID-19 pandemic. Some of these initiatives are new and limited to certain countries and use apps to offer services in isolated situations. In this field, there have also been apps developed in a local context to alert to potential sources of contagion through the smartphone (Lee, 2020). These apps essentially aim to identify sources of contagion more quickly and consequently reduce the rate of spread of the coronavirus. Although the idea is potentially interesting and effective, its adoption is still viewed with some distrust in some countries in the face of the difficulty in guaranteeing full privacy of citizens' data (Abeler et al., 2020). However, the role of technology is even broader. Drones and robots have been used by civil protection authorities to detect and control crowds. The 5G network has also assumed an important role in enabling the functioning of artificial intelligence systems and in facilitating interaction between people who are physically distant (Fisher, 2020).

However, one of the lessons of this crisis is that technology becomes relevant in interaction with people. The Internet has enabled people not only to be consumers of information but also to interact with other people and companies. The channel has progressively become two-way, so technological solutions must not lose focus on people. It is in this context that the concept of Human2Human arises. According to Kramer (2014), in the current information age, people want to be part of something bigger than themselves, feel, and be included. In this context, although people can represent companies and businesses, they are still humans, susceptible to mistakes and emotions. Therefore, Almeida (2020) advocates that it is indispensable for companies to opt for new models of relationship with clients, in which the human component is fundamental in this process, through the establishment of relationships of transparency and trust. This is a central element in the technological solutions that can be developed in the context of this pandemic, in which companies take on the challenge of establishing affective bonds with their clients. 


\subsection{The Emergence of Social Movement Organizations}

Today's society is characterized by being highly diverse and dynamic, in which a huge range of differences coexist daily. The individuals that make up our society have needs embedded in different realities. Staggenborg (2015) notes that these needs, often constituted by minorities, need to be represented in our political context to be met. However, in our society we observe that interests and needs of certain groups are not properly met by government entities. It is from this conflict of interests that social movements become a tool for intervention.

Social movements have emerged to challenge political, economic, and cultural authorities. They also fundamentally arise in times of major emergencies such as calamities and strong repression of individual and collective freedoms (Desposato \& Wang, 2020; Gillan, 2020). As Yadav (2015) argues, social movements are directly linked to solving social problems, rather than to claiming material goods. However, they are not only about claiming rights or demanding representation for a group, because a movement can emerge as a constructive agent of a proposal for social reorganization to change one or another aspect of a society. According to Snow and Soule (2010), a key element of social movements is challenging the authorities by making demands that imply fundamental and structural changes in society. These movements can collaborate with other organizations or associations which allows them to increase their reach and impact on society. The importance of organizing these movements is great for building a more egalitarian and just society (Deveaux, 2018; Laville, 2010). However, the power of collective action is only effective when directed. In this way, the emergence of leaders who directly represent the group's demands and the organization on behalf of common demands or ideas are the pillars and the driving force behind these groups.

Times of deep crisis as currently experienced with COVID-19 can generate the creation of alternative forms of protest and new social movement organizations. Social movements create and recreate links by building on existing networks, but also in their way of acting and connecting that allow these links to multiply (Snow \& Soule, 2009). Faced with the manifest shortcomings of governments and the market, social movement organizations are constituted in mutual support groups that promote social action by helping the most vulnerable populations.

Social movements, in times of deep crisis, are propagated by the perception of a drastic and profound threat, contributing to cognitive openings. While everyday life changes drastically, there are also spaces for reflection on a future that cannot be thought of as a continuation of the past. In this way, reflection in social movements increases our ability to understand the economic, social, and political causes of the pandemic (Pinckney \& Rivers, 2020). Furthermore, social movements can explore the spaces for innovation that arise in times of uncertainty (Farzad et al., 2020; Grasenick \& Guerrero, 2020). The need for sharing and broad support to deal with the pandemic can bring recognition of the richness of civil society mobilization.

In a social movement like Tech4Covid that already features the involvement of many private sector entities, it is important to explore the motivational factors that make this movement grow in an organized and coherent way. A key pillar of the Tech4Covid19 movement is how different organizations and individuals contribute to the development of solutions with high social impact. Another fundamental pillar of this movement is that all the entities participating in this movement do not seek profit and can constitute a non-profit movement that builds a complete support network in multiple areas (e.g., health, education, trade).

In the contextual dimension, the purpose is to characterize the contextual factors where the Tech4Covid19 operates. First, it becomes relevant to define the objective of the organization and the motivations for its emergence considering the perspective of the stakeholders. Equally relevant is to characterize the competition that exists in the area and the cultural barriers that can act as barriers to acceptance of the social movement. Therefore, and to understand the context of the emergence of the Tech4Covid19 movement, the following research questions were established: 
- RQ1. What are the objectives of the Tech4Covid19 movement?

- RQ2. What have been the obstacles encountered in establishing the movement?

- RQ3. What have been the key values transmitted by the movement to people?

In the content dimension, it is relevant to explore the strategic positioning of the social movement and the existing forms of collaboration between its members. In Tech4Covid19 this is an element of great relevance since its members are not permanently allocated to the initiative and perform their professional functions with the business sector, especially with startups incubated in technology parks. Two research questions were established:

- RQ4. What is the organizational structure of the movement?

- RQ5. How is the coordination of the various projects within the movement carried out?

Finally, in the process dimension, it turns relevant to explore the processes associated with the current management of Tech4Covid19 movement. It is explored the ways of balancing work, communication, and distribution channels in the market, and existing transactional costs. Furthermore, and considering the highly unstable and uncertain effects of the pandemic, it is equally relevant to explore the future role of this movement after a few months since its inception. In the end, three more research questions were defined:

- RQ6. What are the selection criteria used for the acceptance/creation of the suggested projects?

- RQ7. What is the expected relationship between the movement and its partners?

- RQ8. What has been the progress of the movement?

Finally, a synthesis of the research questions that have been determined in this study with their associated dimensions is shown in Table 1.

Table 1. Association between dimensions and research questions.

\begin{tabular}{ll}
\hline \multicolumn{1}{c}{ Dimension } & \multicolumn{1}{c}{ Research question } \\
\hline The Context & RQ1. What are the objectives of the Tech4Covid19 movement? \\
& RQ2. What have been the obstacles encountered in establishing the \\
movement? & RQ3. What have been the key values transmitted by the movement to people? \\
RQ4. What is the organizational structure of the movement? & RQ5. How is the coordination of the various projects within the movement \\
carried out? & RQ6. What are the selection criteria used for the acceptance/creation of the \\
suggested projects? & RQ7. What is the expected relationship between the movement and its \\
The Process & RQrtners? \\
&
\end{tabular}

Source: Developed by the authors.

\section{Methodology}

\subsection{Research Design}

The objective of this study is to explore the Tech4Covid19 movement namely to understand how it is possible to organize a movement with these dimensions and characteristics. Furthermore, it aims to assess how this initiative was received by the community, to perceive its internal functioning and organizational dynamics, and to comprehend the strategy defined for the distribution of functions in a highly dynamic and multidisciplinary team. To this end, this study uses both primary and secondary data sources. As primary data sources, an interview with 
the founders of the initiative was conducted and secondary data sources published by the movement on Slack, Instagram, and Facebook social networks were explored.

Figure 1 presents the various phases of the research design. In the contextual dimension, the role of digital technologies in the fight against COVID-19 has been contextualized. Next, a gathering of information on the Tech4Covid19 movement was performed considering secondary data sources. Secondary data sources were used such as social networks (i.e., Slack, Instagram, Facebook), the movement's official web page, and written and digital press news. This information was fundamental to the description of Tech4Covid19 considering its lines of action and evolution over time, both in terms of the composition of its teams and projects. The second phase comprised teamwork and included, in the first place, the definition of the interview structure. After that, the interview was disseminated by the founders of the movement. Given the number of project teams and their distributed organization, the spokesperson of the project was contacted, who then took on the mission of dividing the semi-structured questionnaire by the leaders of their teams. This process took about three weeks until the various responses were compiled into a single written document and verified by the coordination team to check eventual redundant and incomplete information. Finally, in the analytical phase, a thematic analysis of the interview was carried out. This approach has enabled us to identify results and discuss them against the existing literature in the field. Finally, we sought to assess the limitations of this study, and some topics for future research were considered.

Figure 1. Phases of the research design.

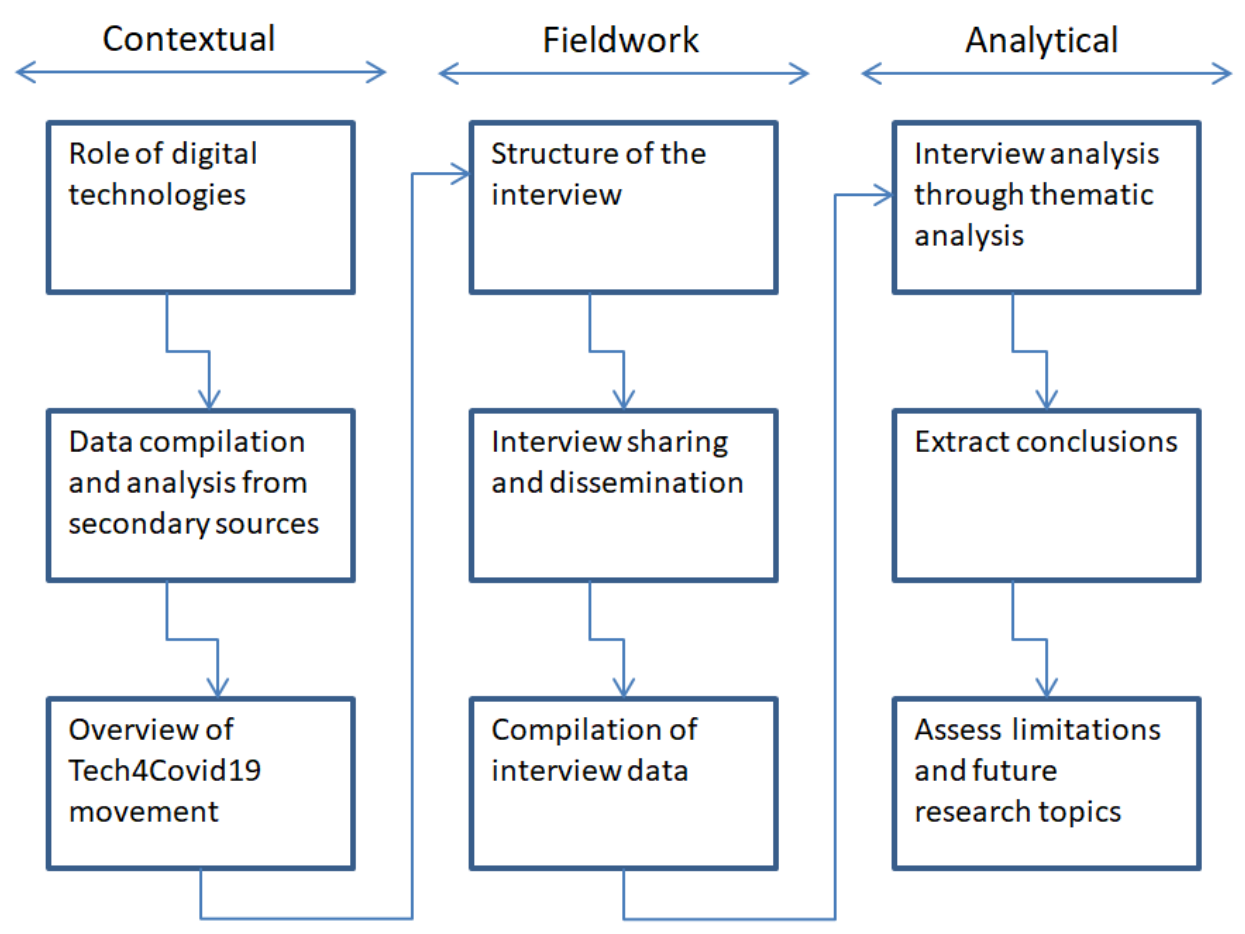

Source: Developed by the authors.

\subsection{Data collection and analysis}

We The semi-structured interview was conducted considering three dimensions of analysis: (i) the context; (ii) the content; and (iii) the process. These dimensions were established with the purpose of understanding the context of the movement's emergence, the decisions taken regarding the organization of the movement and the follow-up given to each project, and the evolution of this project considering the challenges posed by COVID-19. These interviews were 
conducted between May to August 2020. The interviews were transcribed and then loaded into webQDA software to identify common themes for each research question. The themes were generated through a thorough, inclusive, and in-depth coding process. All relevant excerpts were grouped into themes. The different themes were compared to each other and contrasted with the original text. Attention was sought to ensure that each theme is internally coherent, consistent, and distinct from other themes. Table 2 presents the final themes associated with each research question. A total of 22 themes were identified among the 8 established research questions. Among the identified themes emerge the challenges of managing large autonomous teams, the very rapid and accelerated growth of the movement which required changing the movement's organizational paradigm and its communication and coordination dynamics, and the challenges of deconfinement in which emerged the need to ensure a balance between concerns about people's health and the financial sustainability of companies. This balance is a huge challenge and is being explored by several authors such as Gong et al. (2020) and Pronk and Kassler (2020), in which the aim is to minimize economic losses while preserving people's health.

Table 2. Themes associated with the research questions.

\begin{tabular}{|c|c|c|}
\hline Dimension & Research question & Final themes \\
\hline \multirow[t]{10}{*}{ The Context } & RQ1. What are the objectives of the & FT1. Technology-based \\
\hline & Tech4Covid19 movement? & FT2. COVID-19 challenges \\
\hline & & FT3. Common channel \\
\hline & & FT4: Priority areas \\
\hline & RQ2. What have been the obstacles & FT5: Celerity \\
\hline & encountered in establishing the movement? & FT6: Volunteerism \\
\hline & & FT7: Communication \\
\hline & RQ3. What have been the key values & FT8: Transparency \\
\hline & transmitted by the movement to people? & FT9: Solidarity \\
\hline & & $\begin{array}{l}\text { FT10: Technological } \\
\text { ecosystem }\end{array}$ \\
\hline \multirow[t]{6}{*}{ The Content } & RQ4. What is the organizational structure of & FT11: Coordination group \\
\hline & the movement? & FT12: Project managers \\
\hline & & FT13: Spokesperson \\
\hline & RQ5. How is the coordination of the various & FT14: Self-managed teams \\
\hline & projects within the movement carried out? & FT15: Project leader \\
\hline & & FT16: Partnership team \\
\hline \multirow[t]{7}{*}{ The Process } & RQ6. What are the selection criteria used for & FT17: Internal/external \\
\hline & the acceptance/creation of the suggested & projects \\
\hline & projects? & FT18: Alignment \\
\hline & RQ7. What is the expected relationship & FT19: Dedicated team \\
\hline & between the movement and its partners? & FT20: Association \\
\hline & RQ8. What has been the progress of the & FT21: Progressive growth \\
\hline & movement? & $\begin{array}{l}\text { FT22: Deconfinement } \\
\text { challenges }\end{array}$ \\
\hline
\end{tabular}

Source: Developed by the authors. 


\section{Discussion of results}

\subsection{The Context}

The Tech4Covid19 movement brings together engineers, scientists, designers, healthcare professionals, and several other areas who have come together to develop and launch projects, which tend to be technology-based, to mitigate some of the many challenges created by this pandemic context. Initially, the movement focused on the health area and everything related to it, considering the most urgent need/problem or challenge. Some startups already working to fight this pandemic decided to join the movement with their ideas, such as improving the screening of infection networks, facilitating video calls between doctors and patients, creating a support network for displaced doctors and nurses, or even supporting people who simply needed help to go to the grocery store or pharmacy. The second priority area of the movement is education because the Portuguese educational structure was not prepared for distance learning. First, the movement decided to help teachers with two projects: (i) Tools4Edu, consisted of a portal with tutoring to help teachers; and (ii) Student Keep, contributed to combating the problem of inequality in access to education with a sponsorship system. The third major area is the local economy, which consisted of helping local businesses that were strongly affected by the closure of their businesses. One of the most important projects in this area is Preserve, which in practice allows anyone to buy a voucher of their favorite local trade.

The Tech4Covid19 emerged informally and was founded by Portuguese technology startups. This conversation started on March 13, 2020, at WhatsApp grew in just one day to a Slack channel with over 150 people. After 48 hours, more than 300 people were already involved in this movement, in which each member sought to help health professionals and the population according to their specific area of expertise. Although the process of creating this initiative was extremely fast, the objectives were clear and shared by stakeholders as proposed in RQ1. However, some relevant obstacles emerged that are explored in RQ2. The fast evolution of the project required great organization and cooperation between all volunteers and project leaders. In addition to the challenge of creating technologically advanced solutions that would have an immediate impact on society, it was also necessary to ensure the legal and logistical side of the initiative. In this sense, the movement appointed a task force that is responsible for liaison and communication with health institutions. Although there were not exactly any obstacles encountered in the face of the high level of project reception, some lack of celerity felt by some public bodies was notorious, which became more evident in a context of exception and pressure on public bodies.

The existence of social values is a central element in a social movement and leads to the exploitation of RQ3. Transparency is a key value for the Tech4Covid19. The different projects gradually communicate on their websites and respective social networks their state of development, results, and their impact on society. This is done as regularly as possible, ensuring that the information is always up to date for those who follow the movement's initiatives. As Balog-Way and McComas (2020) state, transparency is a fundamental value for society to feel comfortable in getting involved and participating actively in activities in times of pandemic. Tech4Covid19 also intends to convey to the entire population other values. Since this is a movement created by founders of the Portuguese technological community, cooperation and teamwork are other pillars. For that, the Portuguese technological ecosystem was joined around the objective of supporting the Portuguese population in the fight against COVID19. The sharing of knowledge and experience among volunteers belonging to several companies, some of them competitors, ended up creating an even greater link between this sector, which also led to the improvement of the movement's work. Finally, solidarity is a fundamental value in the responses to the COVID-19 pandemic as highlighted by West-Oram (2021), which can be found in all the initiatives that make up Tech4Covid19. The outcomes of the projects only intend to support those who need it most, and there is no monetary benefit. Additionally, almost $100 \%$ of the received 
donations were oriented to the projects and their objectives. Currently, the Tech4Covid19 movement gathers more than 5000 volunteers, 6000 donors, 200 thousand euros raised, and 34 active projects.

\subsection{The Content}

In RQ4 it is revealed the existence of two types of projects are found in the Tech4Covid19 movement: (i) those developed internally and therefore launched by the movement; and (ii) those developed by external entities and supported by the movement. The projects developed and launched by the movement are the result of the work of volunteers. Anyone can join the movement, become a volunteer, and join a project of their choice or who is looking for a person with that know-how. The movement has felt a great adhesion of people to the cause of volunteering in this phase of the pandemic due to factors such as the urgency of this initiative, the motivation to help others, and the search for personal well-being on a physical and emotional level. These elements are aligned with the study carried out by Butt et al. (2017) in which it is mentioned that alignment with the cause and personal beliefs are fundamental elements for companies to engage in volunteer activities. Moreover, and as the startups are essentially made up of young and high qualified professionals, this element has also been a catalyst for the rapid growth of this movement, since as Shah et al. (2015) point out, young people are strongly committed and willing to participate in solidarity initiatives.

Each project is managed by self-managed autonomous teams that address the organizational model posed in RQ5. Each team has a person in charge, who is responsible for reporting to the movement coordination team on its results and evolution. In terms of achieving the results of each initiative, the movement considers that this effort should essentially be made by the teams of the different projects, as they follow their growth and are in touch with those they aim to support. The movement helps each project through human resources and internal organization skills - both through the partnership team, responsible for finding the best companies to support each of the projects, and through the communication and marketing teams, which disseminate information on social networks and ensure media presence. This is relevant work given the many requests the movement have received to participate in public debates and interviews with the media. It also helps to relieve the pressure on the development teams.

\subsection{The Process}

The ideation process up to the launch has some stages, among which the transition from prospect to project, which is dependent on its maturity. In the second case, the companies approach the movement with projects that have already been developed by them. These projects are evaluated considering the terms and conditions of Tech4Covid19, namely whether the product or service has a positive social impact, is solving a problem caused by the pandemic, or complies with the movement's commercial policy. Once these conditions are verified, all project coordinators are consulted to decide whether projects should be supported by the movement and, if so, whether the movement contributes to their promotion. This is the way defined by the movement to evaluate the viability of each project as established in RQ6.

Donations and free services are key elements in answering RQ7. The movement has the support of several companies and institutions that have volunteered to help these projects, both with their talent and sometimes with donations and free services. To work on this front, Tech4Covid19 has a team dedicated exclusively to partnerships that manages the contacts and ensures that the support that arrives is directed to the project of the most appropriate movement.

The exploration of RQ8 allows us to analyze the movement according to the dynamic evolution of the pandemic itself. The Tech4Covid19 has experienced progressive growth, which has been accompanied by the creation of several projects. Despite this evolution, the initial objectives of the movement were only related to solving immediate problems and were not projected in the long term or in a global and integrated way. As the movement identifies a 
problem that they have the capacity to solve, a project is created for this purpose, and its objective is always well defined. It was on this axis that the movement grew until reaching more than 30 active projects today. Despite their high number, they also had to follow the pandemic situation itself, about the risk of no longer making sense or being necessary anymore. In this sense, it is essential to ensure constant innovation and adaptation of the solution. Innovation can take multiple perspectives. On a more technological level, it has enabled the creation of technologically advanced projects as a means of diagnosis and detection of COVID-19, but it has also encouraged the emergence of new channels of communication and collaborative work on cloud environments (Sheridan, 2020).

The current deconfinement is bringing new challenges to society, since more than a health crisis, we are now facing a major economic crisis and, consequently, several projects have been launched to address this front. An example of this is TeamLoan, a platform that aims to match companies that need to strengthen their team and companies that, on the contrary, are struggling to secure some jobs. The platform matches the needs and promotes an agreement between the two companies so that the work of the employee is guaranteed. Several companies have joined this platform in areas such as accommodation, food retail, catering, social service, and entertainment. A change of focus is evident in the movement that was initially primarily directed at the health area but quickly expanded into the economic and social spheres.

The movement is also focused on ensuring that if the 2nd wave of the disease spreads, the projects remain active, or can reactivate in a short period of time to help the population again. Finally, many of the needs that arise with isolation remain and, therefore, most of the projects launched by the movement remain valid.

\section{Conclusions}

The rapid spread of COVID-19 led the Portuguese technological startups to come together to implement a movement entitled Tech4Covid19 that aims, through the development of technological solutions, to provide the necessary tools to stop this outbreak and assist the Portuguese in this period of isolation. The Tech4Covid19 movement is based on three major domains such as health, education, and local economy. This non-profit movement gathers professionals from the most varied areas, from health professionals, scientists, engineers, designers, to other specialties, with the objective of developing numerous projects that can mitigate the consequences of this pandemic, as well as promoting support to health professionals and access to hospital equipment.

Organizing a movement with over 5000 volunteers, 6000 donors, and 34 active projects is a demanding challenge, namely to ensure that each volunteer is collaborating on projects in their area of interest and competence, and in communication between the various groups and members. The movement simultaneously includes internal projects developed by its teams but also accepts external projects that are aligned with the principles and values of the movement. Although the movement emerged informally in WhatsApp and supported its internal communication on the Slack platform, it became necessary to establish some more formalism by forming an association for this purpose. This was a key element in legal, accounting, and transparency terms to enable the collection of donations and the establishment of formal partnerships with the business sector. The movement has been a progressive growth in both the number of volunteers involved and active projects, which means that the needs caused by the pandemic are still present. Currently, the great challenge is to keep the movement operational and the projects active, avoiding redundancy and duplication of effort between them. Also important is to consider the new challenges posed by the several waves and variants of COVID19 , and the emergence of digital vaccination certificates.

This paper offers essentially practical contributions by helping to understand and explore the organizational model and dynamics of Tech4Covid19. This is one of the most important technological movements in the fight against the consequences of COVID-19 in society and 
contributed decisively to the appearance of technology-based innovative projects. This study allows practitioners to learn how a social movement can be formed and organized to meet the challenges posed by COVID-19. It also highlights how technology can be used to build inclusive solutions to bring people together and address health, economic, and social challenges. The main limitation of the study is the highly dynamic nature of this movement in a context of great uncertainty; hence it is difficult to predict the sustainability of most of these initiatives in the near future. Other limitations can also be pointed out. This study did not explore the effects of the Tech4Covid19 dimension and mission on the findings assuming that the challenges posed to each self-managed autonomous team are similar. Neither was explored the receptivity of the projects developed particularly with the most vulnerable population. The support of this project mainly in cloud and mobile technologies brings more difficulties to the most disadvantaged segments of society. As future work, it is intended to carry out an exploratory and benchmarking study that can compare the various initiatives to combat the effects of COVID-19, in an attempt to identify convergent and divergent points between them. It will also be relevant to explore the barriers to the adoption of each project considering its beneficiaries and to include minority populations in these groups to realize to what extent these projects contribute to social inclusion.

\section{References}

Abeler, J., Bäcker, M., Buermeyer, U., \& Zillessen, H. (2020). COVID-19 Contact Tracing and Data Protection Can Go Together. JMIR mHealth and uHealth, 8(4), e19359. https://mhealth.jmir.org/2020/4/e19359/

Almeida, F. (2020). The Concept of Human2Human In The Response To COVID-19. International and Multidisciplinary Journal of Social Sciences, 9(2), 129-151. https://doi.org/10.17583/rimcis.2020.5524

Belzunegui-Eraso, A., \& Erro-Garcés, A. (2020). Teleworking in the Context of the Covid-19 Crisis. Sustainability, 12(9), 1-18. https://doi.org/10.3390/su12093662

Butt, M. U., Hou, Y., Soomro, K. A., \& Maran, D. A. (2017). The ABCE Model of Volunteer Motivation. Journal of Social Service Research, 43(5), 593-608. https://doi.org/10.1080/01488376.2017.1355867

Dahlin, E. (2019). Are Robots Stealing Our Jobs? Socius: Sociological Research for a Dynamic World, 5, 1-14. https://doi.org/10.1177/2378023119846249

Desposato, S., \& Wang, G. (2020). The long-term impact of social movements and repression on democratic attitudes. Journal of East Asian Studies, 20(3), 317-351. https://doi.org/10.1017/jea.2020.16

Deveaux, M. (2018). Poor-Led Social Movements and Global Justice. Political Theory, 46(5), 698-725. https://doi.org/10.1177/0090591718776938

Farzad, F. S., Yashar, S., Amran, A. B., \& Hafezalkotob, A. (2020). Social innovation: Towards a better life after COVID-19 crisis: What to concentrate on. Journal of Entrepreneurship, Business and Economics, 8(1), 89120. http://scientificia.com/index.php/JEBE/article/view/131

Fisher, W. (2020). COVID-19 Speeds the Race for 5G. Retrieved from https://www.e-ir.info/2020/06/29/covid19-speeds-the-race-for- $5 \mathrm{~g} /$

Gentili, A., Compagnucci, F., Gallegati, M., \& Valentini, E. (2020). Are machines stealing our jobs? Cambridge Journal of Regions, Economy and Society, 13(1), 153-173. https://doi.org/10.1093/cjres/rsz025

Gillan, K. (2020). Temporality in social movement theory: vectors and events in the neoliberal timescape. Social Movement Studies, 19(5-6), 516-536. https://doi.org/10.1080/14742837.2018.1548965 
Giones, F., Brem, A., Pollack, J. M., Michaelis, T. L., Klyver, K., \& Brinckmann, J. (2020). Revising entrepreneurial action in response to exogenous shocks: Considering the COVID-19 pandemic. Journal of Business Venturing Insights, 14, e00186. https://doi.org/10.1016/j.jbvi.2020.e00186

Gong, B., Zhang, S., Yuan, L., \& Chen, K. Z. (2020). A balance act: minimizing economic loss while controlling novel coronavirus pneumonia. Journal of Chinese Governance, 5(2), 249-268. https://doi.org/10.1080/23812346.2020.1741940

Grasenick, K., \& Guerrero, M. (2020). Responsible Research and Innovation \& Digital Inclusiveness during Covid-19 Crisis in the Human Brain Project (HBP). Journal of Responsible Technology, 1, 1-2. https://doi.org/10.1016/j.jrt.2020.06.001

Hennig, B. D. (2020). COVID-19's Spread Across the World. Political Insight, 11(2), 20-21. https://doi.org/10.1177/2041905820933370

Kramer, B. (2014). There is No B2B or B2C: It's Human to Human. Substantium.

Laville, J. L. (2010). The Solidarity Economy: An International Movement. RCCS Annual Review, 2(2), 1-41. https://doi.org/10.4000/rccsar.202

Lee, B. Y. (2020). To Help Stop COVID-19 Coronavirus, What Is Contact Tracing, How Do You Do It. Retrieved from https://www.forbes.com/sites/brucelee/2020/04/17/what-is-contact-tracing-why-is-it-key-to-stopcovid-19-coronavirus/\#5bdb04ca3e5e

LeRoux, K. (2009). Managing stakeholder demands. Balancing responsiveness to clients and funding agents in nonprofit social service organizations. Administration $\mathcal{E}$ Society, 41(2), 158-184. https://doi.org/10.1177/0095399709332298

Marques, A. P., \& Couto, A. I. (2017). SMEs and Family Smes: Specificities from the Portuguese SocioBusiness Contex. European Journal of Economics and Business Studies, 3(2), 190-199.

Pinckney, J., \& Rivers, M. (2020). Sickness or silence. Journal of International Affairs, 73(2), 23-42.

Pronk, N., \& Kassler, W. (2020). Balancing Health and Economic Factors when Reopening Business in the Age of COVID-19. Journal of Occupational and Environmental Medicine, In Press.

Seijts, G., \& Milani, K. Y. (2020). The myriad ways in which COVID-19 revealed character. Organizational Dynamics, 50(3), 100765. https://doi.org/10.1016/j.orgdyn.2020.100765

Shah, J. A., Suandi, T., Hamzah, S. R., \& Ismail, I. A. (2015). Why Youths Choose to Become Volunteers: From the Perspective of Belief. Athens Journal of Social Sciences, 2(1), 51-64. https://doi.org/10.30958/ajss.2-1-4

Sheridan, C. (2020). COVID-19 spurs wave of innovative diagnostics. Nature Biotechnology, 38, 769-772.

Simões, L. (2020). OECD: Portugal is the country with the most innovative projects to combat Covid-19. Retrieved from https://jornaleconomico.sapo.pt/en/news/ocde-portugal-and-the-country-with-more-innovativeprojects-to-combat-covid-19-578610

Snow, D. A., \& Soule, S. A. (2010). A primer on social movements. W. Norton.

Staggenborg, S. (2015). Social Movements. Oxford University Press.

West-Oram, P. (2020). Solidarity is for other people: identifying derelictions of solidarity in responses to COVID-19. Journal of Medical Ethics, 47, 65-68. http://dx.doi.org/10.1136/medethics-2020-106522 
Yadav, A. K. (2015). Social Movements, Social Problems and Social Change. Academic Voices: A Multidisciplinary Journal, 5, 1-4. https://doi.org/10.3126/av.v5i0.15842

\section{@ (요 $\Theta \Theta$}

(C) Attribution-NonCommercial-NoDerivatives 4.0 International (CC BY-NC-ND 4.0)

https://creativecommons.org/licenses/by-nc-nd/4.0/ 